\title{
COMPARISON OF ICE CRYSTALS GROWN FROM VAPOUR IN VARYING CONDITIONS
}

by

\author{
akira Yamashita, Asaharu asano and Takayuki OHno
}

Osaka Kyoiku University, Tennoji-ku, Osaka, Japan 543

\section{ABSTRACT}

In a static supercooled cloud dendrites hardly grow at about $-15^{\circ} \mathrm{C}$ except at the pointed tip of a needle-like ice crystal or an isolated thin plate-like ice crystal. When ice crystals are moved slowly in a static supercooled cloud, dendrites grow at about $-15^{\circ} \mathrm{C}$ and the $a$-axis growth rate increases as the velocity of the dendrites increases; at velocities higher than $20 \mathrm{~cm} / \mathrm{s}$, however, the $a$-axis growth rate decreases as the velocity increases due to the influence of heavy riming. The maximum $a$-axis growth rate in a supercooled cloud is observed at about $-15^{\circ} \mathrm{C}$ in experiments growing ice crystals in free fall.

\section{INTRODUCTION}

Influence of air velocity on ice crystal growth has been discussed recently by Kuroda (1982 and 1983), and investigated experimentally over a wide range of ambient supersaturations and temperatures, and at velocities lower than $10 \mathrm{~cm} / \mathrm{s}$ by Keller and Hallett (1982). The present paper also describes the influence comparing the results of three different experiments.

\section{EXPERIMENTS}

Experiment I: growth in free fall (Yamashita 1973 and 1974)

A cloud chamber, about $15 \mathrm{~m}$ high, was used in experiments growing ice crystals in a supercooled cloud in free fall.

Experiment II: growth in a static cloud

An unforced air flow cloud chamber was used in experiments growing ice crystals in a static supercooled cloud; mean horizontal air velocity was less than 0.3 $\mathrm{cm} / \mathrm{s}$ in the present study. Design of the apparatus and

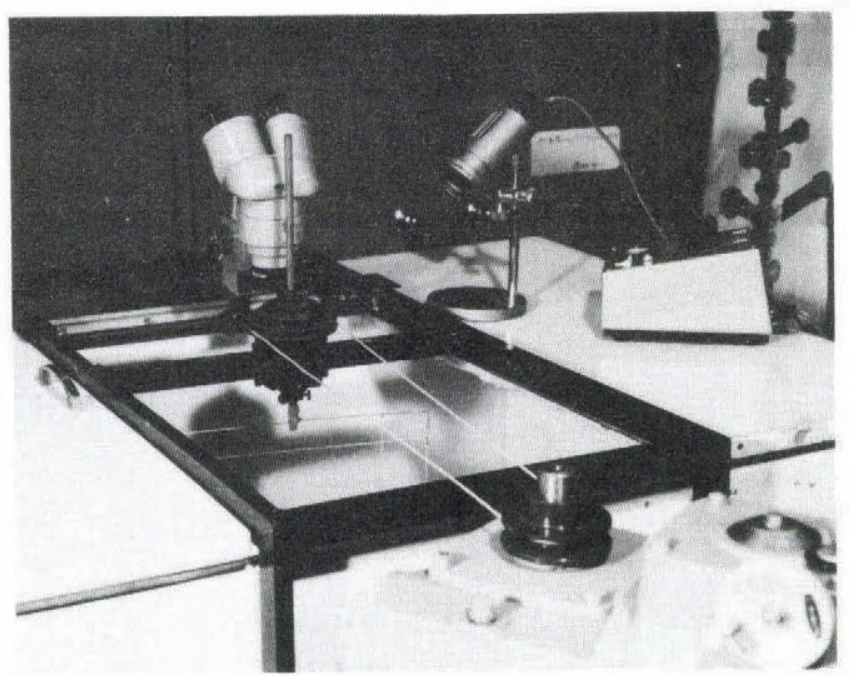

Fig.1. Apparatus for growing ice crystals rotating in a supercooled cloud. The frame rotates in an unforced air flow cloud chamber with an inside volume of 500 litres. experimental procedures are shown in an earlier paper (Yamashita and Ohno 1984).

Experiment III: growth in air flow

An unforced air flow cloud chamber of about 500 liters was used in growing ice cystals in air flow. Figure 1 shows the cloud chamber and the apparatus used to rotate growing ice crystals. When the metal frame with vertical and horizontal threads $(0.1 \mathrm{~cm}$ in diameter and $30 \mathrm{~cm}$ in length) is rotated in a static supercooled cloud, ice crystals start to grow on the threads within 30 minutes. At this stage the horizontal thread is dropped or raised to the level where ice crystals on the vertical thread have grown largest, and the frame is rotated again after all the ice crystals grown on the horizontal thread are completely removed. The temperature at the level of the horizontal thread is measured before and after the rotating experiment, and

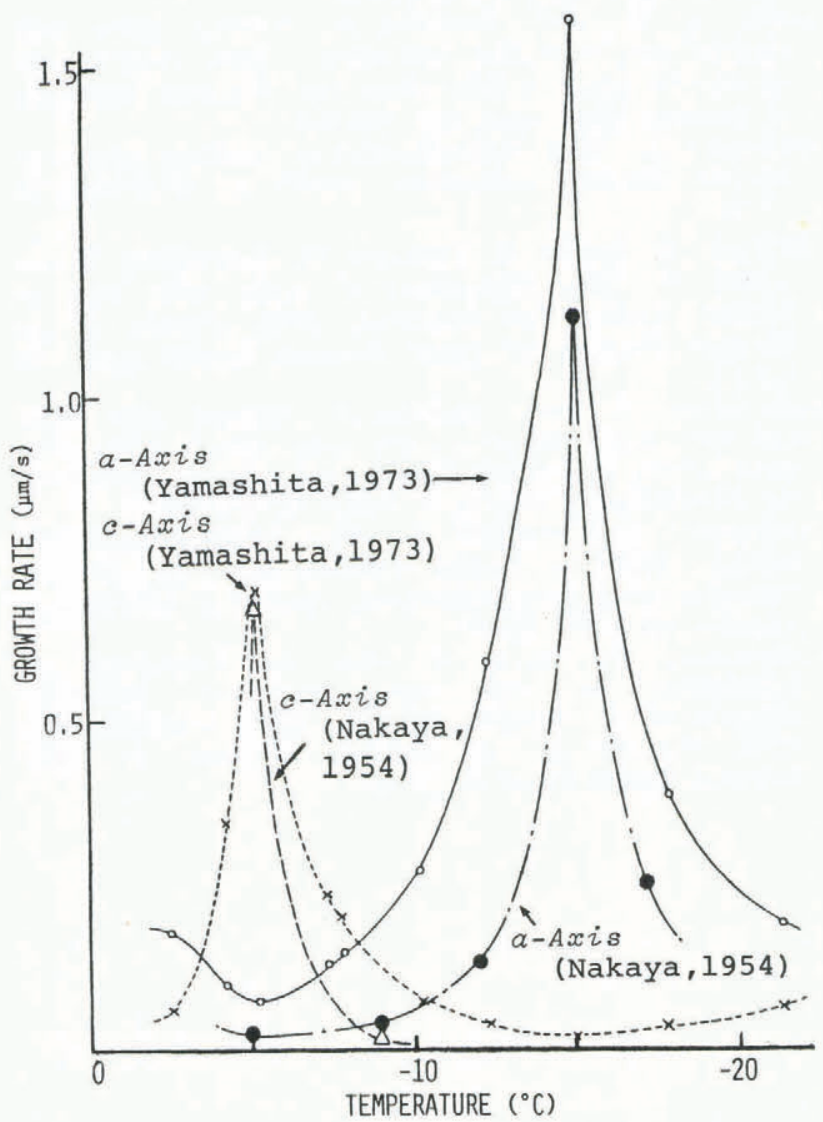

Fig.2. Growth rates of falling ice single crystals in their initial growth stage. The values were obtained by observing the sizes of ice crystals grown from submicron sized initial crystals for 200 seconds. Those from Nakaya (1954) are also shown. 
it is confirmed that ice crystals have grown at temperatures between -14 and $-15^{\circ} \mathrm{C}$ on the thread. Growth rates are measured by observing ice crystals every 30 minutes under a microscope having a long working distance. Grown ice crystals are also sampled and observed in detail in a cold room when necessary.

\section{RESULTS}

Growth rates along the $c$ - and $a$ - axes of single crystals fallen in a supercooled cloud are shown in Figure 2. In this experiment (Experiment I) ice crystals

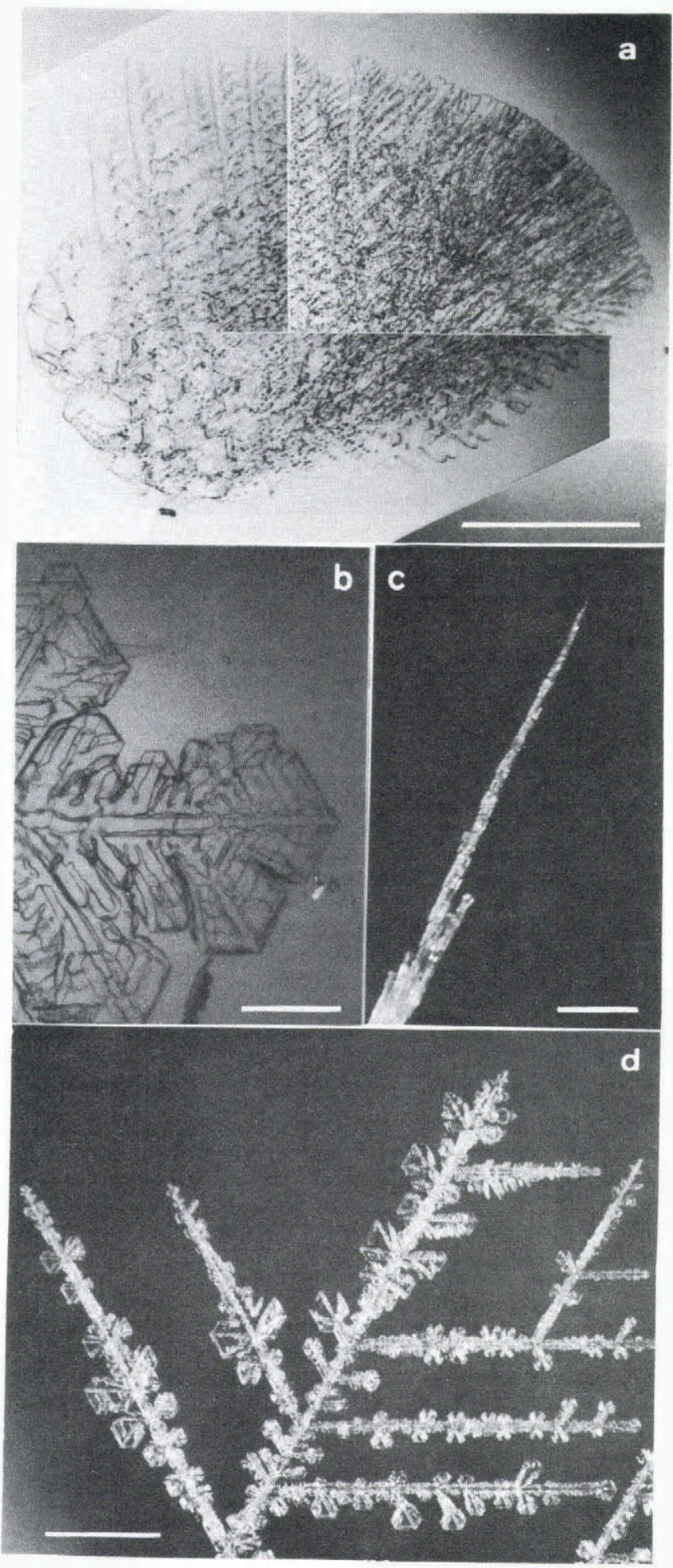

Fig.3. Ice crystals grown in a static supercooled cloud. a: plate having a circular periphery in part, $-2 \sim-1{ }^{\circ} \mathrm{C}$; b: sector plate, $-4^{\circ} \mathrm{C}$; c: needle, $-5^{\circ} \mathrm{C}$; d: dendrite, $-15^{\circ} \mathrm{C}$. Scales in a, c and d: $2 \mathrm{~mm}$; in b: $0.2 \mathrm{~mm}$. were produced by the sudden expansion of compressed air $(\approx 0.1 \mathrm{ml})$ in a supercooled cloud. Growth rates were obtained by observing the sizes of ice crystals grown for 200 seconds in the cloud. Growth rates of artificial snow crystals calculated from Nakaya (1954), are also shown in the figure.

Ice crystals shown in Figure 3a-d were grown in a static supercooled cloud on vertically suspended threads, or on frost in an unforced air flow cloud chamber (Experiment II). At temperatures higher than about $-7^{\circ} \mathrm{C}$, ice crystal types shown in Figure $3 a$ to $3 c$ were always observed on the vertical threads or on frost if the growth location was within the supercooled cloud. The dendrite shown in Figure 3d was of a type which rarely grew in this experiment. In a static supercooled cloud, no dendrites grew from frozen water drops or from seeded thin plate-like ice crystals densely captured on a
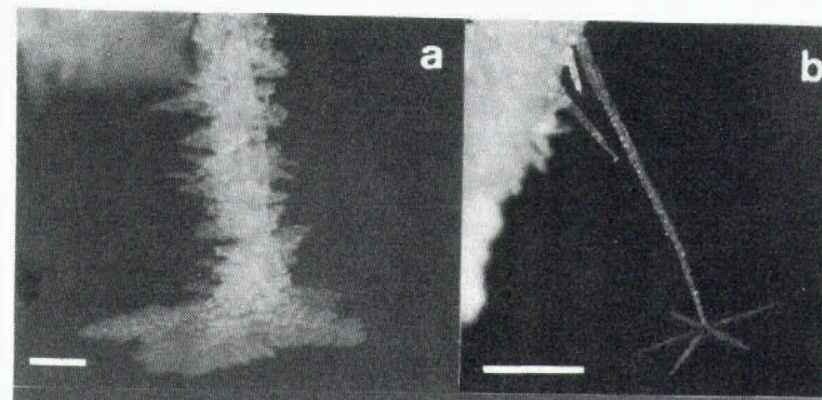

c
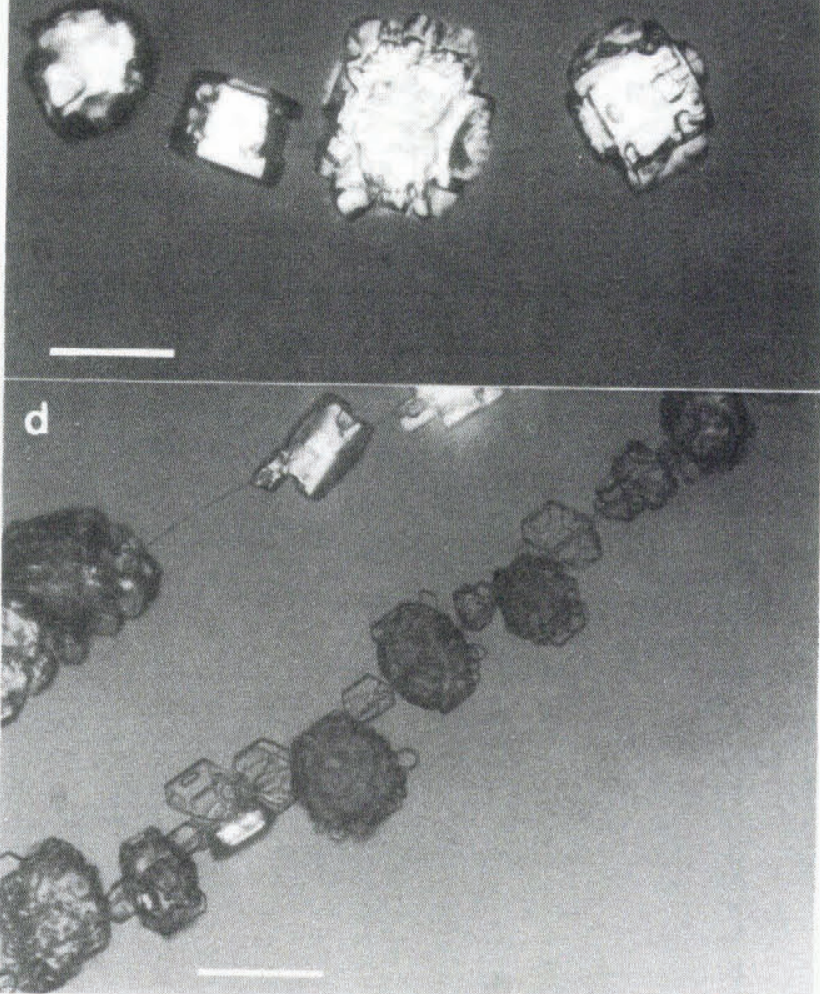

Fig.4. Ice crystals grown in a static supercooled cloud. a plates grown in the temperature range -1.5 to $-4{ }^{\circ} \mathrm{C}$ on a needle; b: dendrite grown at about $-15^{\circ} \mathrm{C}$ on a needle tip; c: frozen water drops grown for an hour at about $-15^{\circ} \mathrm{C}$. (Dendrites had never grown from frozen water drops.) d: frozen water drops and thin plates grown for half an hour at about $-15^{\circ} \mathrm{C}$. (No dendrites had grown from these ice crystals.) Scales in a and b: $2 \mathrm{~mm}$; in c and $\mathrm{d}: 0.2 \mathrm{~mm}$. 
thread at about $-15^{\circ} \mathrm{C}$ (as shown in Figure $4 \mathrm{c}$ and $4 \mathrm{~d}$ ). It was necessary to capture a few seeded thin plate-like ice crystals with a sufficient spacing greater than $2 \mathrm{~cm}$ in order to grow dendrites from them in this condition. The crystal of Figure $4 a$ was grown in a static supercooled cloud by the following method. When a needle-like crystal grew on the thread at a level of about $-5^{\circ} \mathrm{C}$, it was raised to another level of temperature between -4 and $-1.5^{\circ} \mathrm{C}$ by lifting the thread upward, allowing many plate-shaped crystals to grow on this initial crystal. Figure 4b shows an ice crystal grown in a static supercooled cloud in a similar way. That is, an initial needle-like crystal was dropped to the level of temperature about $-15^{\circ} \mathrm{C}$. In this case a dendrite grew from a tip of the needle. Repeated 10 times, it was found that a dendrite always grew from a tip of a needle-like crystal, provided that the crystal was dropped to the level of temperature about $-15^{\circ} \mathrm{C}$ in the static supercooled cloud.

Growth rates along $c$ - and $a$-axes of single crystals in Experiment II are shown in Figure 5. In this figure the $a$-axis growth rate of dendrites, which was markedly large, is shown independently because their growth

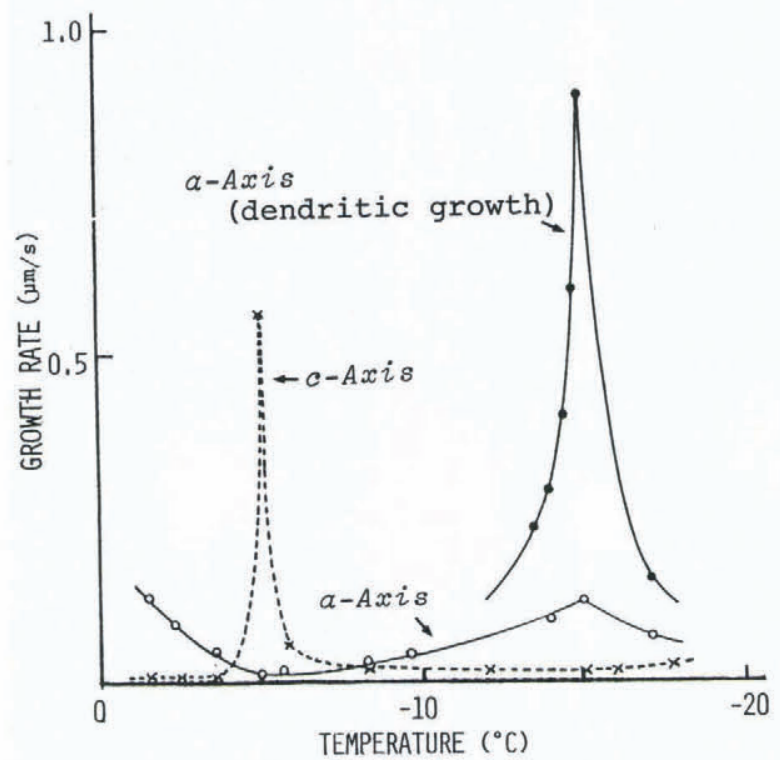

Fig.5. Growth rates of ice single crystals grown in a static supercooled cloud. (Dendrites grew rarely on frost or on threads.)

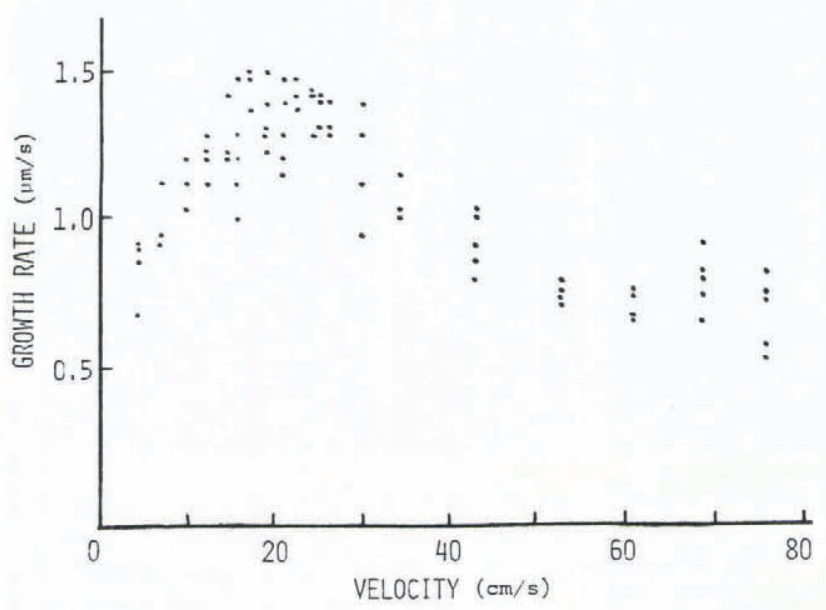

Fig.6. $a$-axis growth rate of dendrites as a function of air velocity (at velocities between 4 and $60 \mathrm{~cm} / \mathrm{s}$ ). At velocities higher than $60 \mathrm{~cm} / \mathrm{s}$, the maximum linear growth rate of polycrystals is shown.
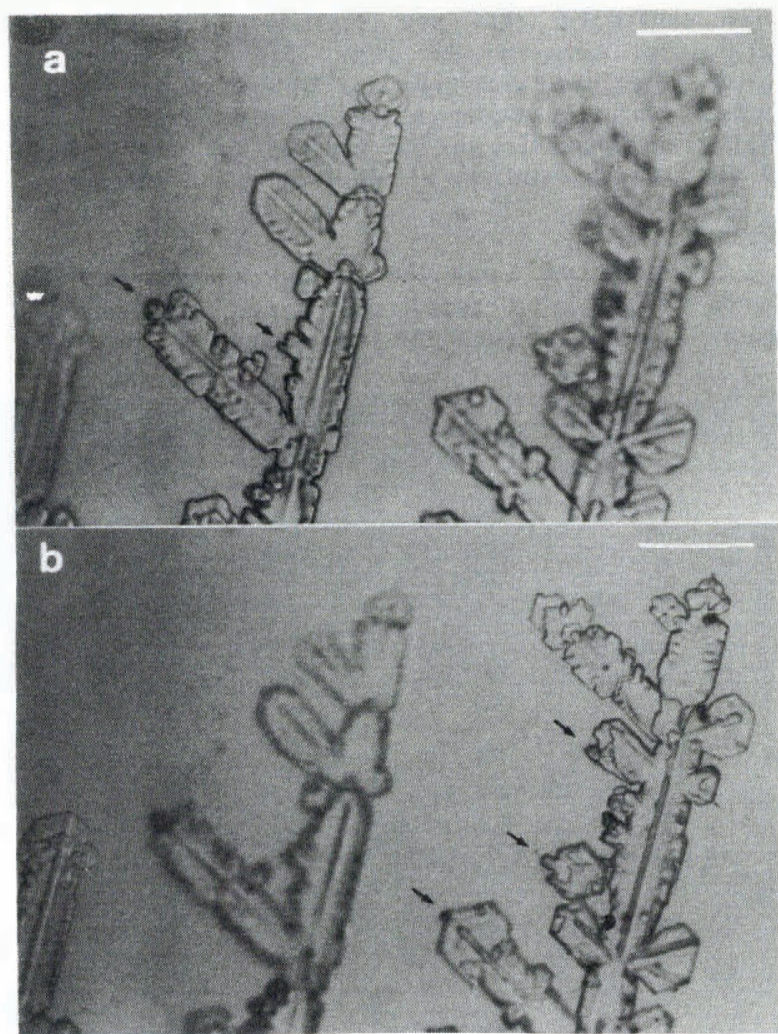

Fig.7. A dendrite having a multi-layered construction. Air velocity: $10 \mathrm{~cm} / \mathrm{s}$; scales: $0.1 \mathrm{~mm}$; arrows: rimed droplets at edges or corners.

occurred only under rather exceptional conditions, as shown above.

Measurements of the $a$-axis growth rate of dendrites in a static supercooled cloud, at velocities between 4 and $60 \mathrm{~cm} / \mathrm{s}$ are shown in Figure 6 (Experiment III). In this figure, the growth rate in the direction of the maximum growth of polycrystalline ice is shown instead of the $a$-axis growth rate of dendrites at velocities greater than $60 \mathrm{~cm} / \mathrm{s}$, because no dendrites were observed in this velocity range. It can be seen that there is a peak in the $a$-axis growth rate of dendrites at a velocity about $20 \mathrm{~cm} / \mathrm{s}$. Figure 7 shows a dendrite grown at velocity $10 \mathrm{~cm} / \mathrm{s}$. A few parallel layers, which are inferred to have grown from cloud droplets rimed at the pointed parts of the crystal, appear in this photograph.

\section{CONCLUSIONS AND FURTHER DISCUSSION}

Variations in ice crystal habit with temperature, observed in experiments of growing single crystals in a static supercooled cloud, were similar to those observed in experiments growing single crystals in free fall in a supercooled cloud, and they virtually agreed with variations in the basic habits of ice crystals with temperature, investigated in detail for a long time. In a static supercooled cloud, however, dendrites hardly grew at about $-15^{\circ} \mathrm{C}$ except at the pointed tip of a needle-like ice crystal or an isolated thin plate-like ice crystal.

The $a$-axis growth rate of dendrites at about $-15^{\circ} \mathrm{C}$ in a supercooled cloud increased as the velocity of the dendrites was increased, at velocities between 4 and 20 $\mathrm{cm} / \mathrm{s}$. This increase of the $a$-axis growth rate is attributed to the influence of air velocity as Keller and Hallett (1982) have investigated. Meanwhile, at velocities higher than about $10 \mathrm{~cm} / \mathrm{s}$, riming was found to occur on the surface of ice crystals; at velocities higher than $20 \mathrm{~cm} / \mathrm{s}$, the $a$-axis growth rate decreased as the velocity increased. This decrease of the $a$-axis growth rate seems to be attributable to the influence of heavy riming. Large values of the growth rates along $c$ - and $a$-axes, observed in experiments of growing ice crystals in free 
fall in a supercoooled cloud, may be attributed to falling motion of crystals in their early growth stage. The $a$-axis growth rate of freely falling dendrites at $-14.8^{\circ} \mathrm{C}$ in a supercooled cloud was greater than the maximum $a$-axis growth rate observed while growing dendrites in an air flow. The deviation of growth from along the $a$-axis, observed by Keller and Hallett (1982) in a ventilated experiment at about $-14^{\circ} \mathrm{C}$, was not observed in the present experiment, although experimental data in the present study were limited.

The role of mixing in a supercooled cloud by rotating ice crystals was neglected in the present experiment because the moving velocity of the cloud just after the rotation stopped was less than $10 \%$ of the initial velocity of ice crystals, at initial velocities between 4 and $20 \mathrm{~cm} / \mathrm{s}$.

\section{ACKNOWLEDGEMENTS}

The authors thank Mr $\mathrm{S}$ Miki and Miss $M$ Yamasaki for their valuable help in carrying out the experiments.

\section{REFERENCES}

Keller V W, Hallett J 1982 Influence of air velocity on the habit of ice crystal growth from the vapor. Journal of Crystal Growth 60: 91-106

Kuroda T 1982 Growth kinetics of ice single crystal from the vapour phase and variation of its growth form. Journal of the Meteorological Society of Japan 60:

Kuroda T 1983 Recent developments in theory and experiment of growth kinetics of ice crystals from the vapour phase and their growth forms. Journal of Crystal Growth 65: 27-35

Nakaya U 1954 Snow crystals. Harvard University Press, Boston

Yamashita A 1973 On the trigonal growth of ice crystals. Journal of the Meteorological Society of Japan 51: 307-317

Yamashita A 1974 [Ice crystals grown in free fall in a large cloud chamber] (in Japanese). Meteorological Research Notes 123: 813-860

Yamashita A, Ohno T 1984 Ice crystals grown in an unforced air flow cloud chamber. Journal of the Meteorological Society of Japan 62: 135-139 